Approved for public release; distribution is unfimited.

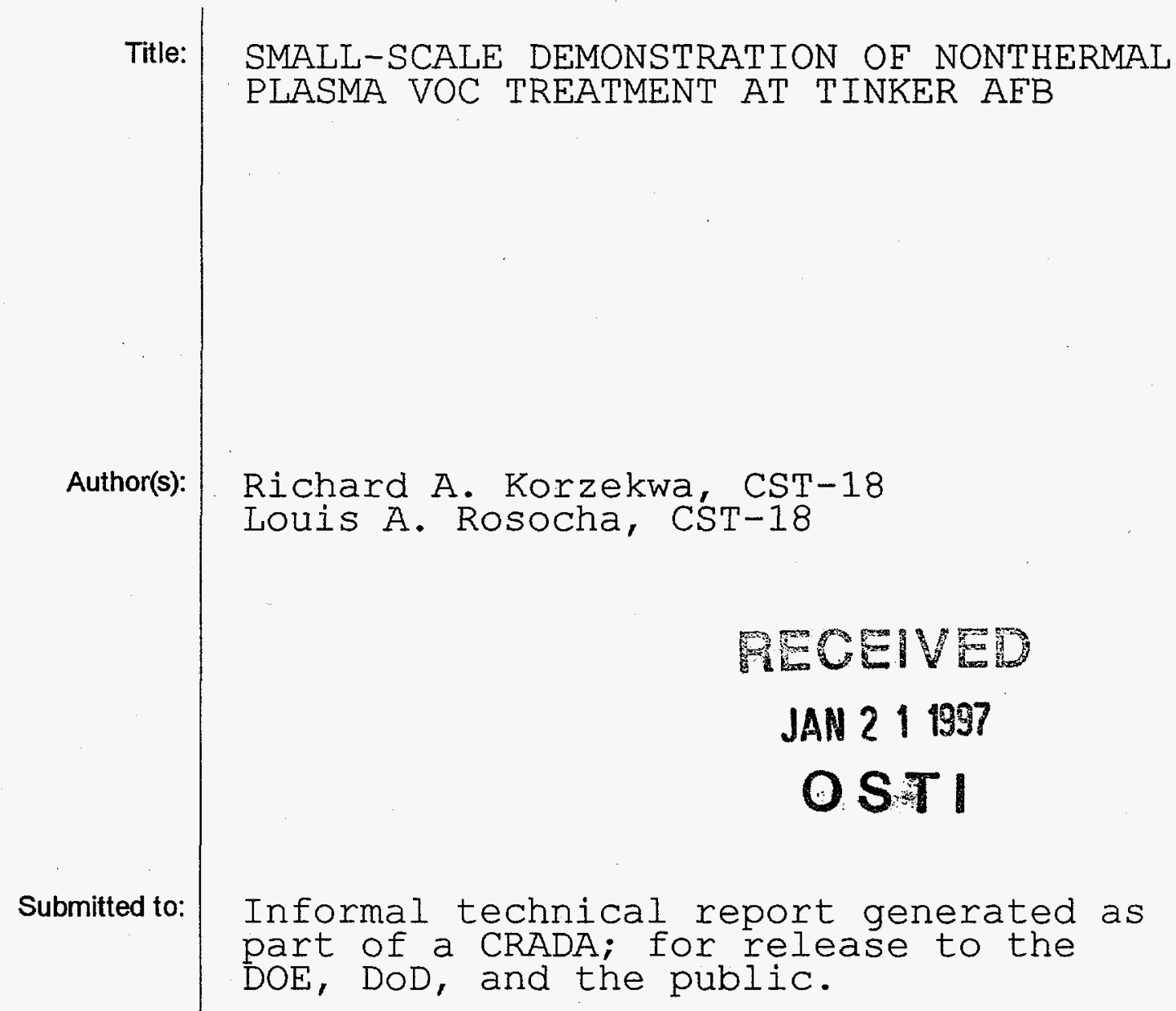

DISCLAIMER

This report was prepared as an account of work sponsored by an agency of the United States Government. Neither the United States Government nor any agency thereof, nor any of their employees, makes any warranty, express or implied, or assumes any legal liability or responsibility for the accuracy, completeness, or usefulness of any information, apparatus, product, or process disclosed, or represents that its use would not infringe privately owned rights. Reference herein to any specific commercial product, process, or service by trade name, trademark, manufacturer, or otherwise does not necessarily constitute or imply its endorsement, recommendation, or favoring by the United States Government or any agency thereof. The views and opinions of authors expressed herein do not necessarily state or reflect those of the United States Government or any agency thereof.

Los Alamos National Laboratory, an affirmative action/equal opportunity employer, is operated by the University of California for the U.S. Department of Energy under contract W-7405-ENG-36. By acceptance of this article, the publisher recognizes that the U.S. Govemment retains a nonexclusive, royalty-free license to publish or reproduce the published form of this contribution, or to allow others to do so, for U.S. Government purposes. Los Alamos National Laboratory requests that the publisher identify this article as work performed under the auspices of the U.S. Department of Energy. The Los Alamos National Laboratory strongly supports academic freedom and a researcher's right to publish; as an institution, however, the Laboratory does not endorse the viewpoint of a publication or guarantee its technical correctness. 


\section{DISCLAMMER}

Portions of this document may be illegible in electronic image products. Images are produced from the best available original document. 


\section{Small-Scale Demonstration of Nonthermal Plasma VOC Treatment at Tinker AFB}

Los Alamos National Laboratory

Electric Power Research Institute

Tinker Air Force Base

CRADA\# LA93C10100

Richard A. Korzekwa \& Louis A. Rosocha

Los Alamos National Laboratory

October 22, 1996 


\title{
Small-Scale Field Demonstration of Nonthermal Plasma VOC Treatment at Tinker AFB
}

\author{
Richard A. Korzekwa and Louis A. Rosocha \\ Los Alamos National Laboratory
}

October 22, 1996

\section{Introduction}

Nonthermal plasma (NTP) technology is a promising candidate for the treatment of air pollutants [1]. An NTP is different from a thermal plasma in that high energy electrons are used to create chemically active species without raising the gas to high temperatures. NTPs have the potential of simultaneous removal of multiple air pollutants with better control over treatment byproducts. A silent discharge plasma (SDP) configuration is one method of easily generating such a nonthermal plasma [2].

Silent electrical discharge plasma (dielectric barrier) reactors can decompose gas-phase pollutants by free-radical attack or electron-induced fragmentation. The radicals or electrons are produced by the large average volume nonthermal plasmas generated in the reactor. In the past decade, the barrier configuration has attracted attention for destroying toxic chemical agents for the military, removing harmful greenhouse gases (oxides of sulfur and nitrogen - $\mathrm{SO}_{\mathrm{x}}$ and $\mathrm{NO}_{\mathrm{x}}$ ), and treating other environmentally-hazardous chemical compounds (hydrocarbons, chlorocarbons, and chloro-fluorocarbons). At the Los Alamos National Laboratory (LANL), we have been studying the silent discharge plasma for processing gaseous-based hazardous chemicals for approximately five years [3]. The key objective is to convert hazardous or toxic chemicals into non-hazardous compounds or into materials which are more easily managed. The main applications have been for treating off-gases from thermal treatment units (e.g., incinerators, hightemperature packed bed reactors; arc melters; low-temperature thermal desorbers), and for abating hazardous air-pollutant emissions (e.g., industrial air emissions, vapors extracted from contaminated soil or groundwater). An overview of SDP technology is presented in Appendix A.

In 1992, a collaborative agreement was negotiated between LANL and the Electric Power Research Institute (EPRI) to develop SDP technology for the treatment of industrial hazardous air emissions. Under that partnership, a small-scale, mobile unit was designed and constructed for industrially-relevant field demonstrations. Because the Tinker AFB has been actively engaged in programs on the environment and because such a large base mirrors many industrial environmental concerns, testing the SDP unit at Tinker was considered beneficial for all three parties. Therefore, this demonstration at Tinker AFB was a collaborative effort between LANL, EPRI, and the air force base. EPRI 
contributed funding for the construction of the trailer, LANL designed and constructed the SDP system and provided the expertise for operation and chemical analysis. Tinker AFB provided the site facilities (water treatment operation) and necessary equipment for setup and installation. The tests were carried out during March 25-29, 1996. Appendix B presents a summary of the EPRI-LANL collaboration and a brief overview of the mobile SDP treatment unit.

At the Tinker site, historical pollution of the groundwater from the use of industrial solvents (i.e., VOCs - volatile organic compounds) is being remediated by a conventional pump-and-treat (P\&T) system. At the P\&T facility, groundwater is pumped out through wells and delivered to a vacuum-sparger where the solvents are transferred to the vapor phase in an air stream. This vapor-laden air stream is then directed to activated carbon absorbers where the solvents are captured for later disposal. The solvent concentrations in the groundwater are quite small, resulting in low vapor-phase concentrations in the extracted air stream. Measurements of contaminant concentrations in the air stream have shown typical maximum values of approximately $6 \mathrm{ppm}$ for TCE (trichloroethylene), $1 \mathrm{ppm}$ for $\mathrm{DCE}$ (1,2 dichloroethylene), $2 \mathrm{ppm}$ for toluene, and less than $1 \mathrm{ppm}$ for xylene and acetone.

One of our key goals was to assess the performance of the SDP process in removing such low concentrations of VOCs. Because the airstream concentrations of the VOCs at Tinker are very close to the air-emissions standards, only a low degree of removal is required which could make the SDP process economics more favorable. Also, the SDP unit can serve as a pretreatment stage for carbon units. Such a combined system is projected to significantly reduce the cost of carbon-absorber based treatment of VOCs.

\section{Experimental Equipment and Procedures}

\section{Pre-Field Laboratory Tests}

Before carrying out field tests, laboratory experiments were conducted to measure the decomposition characteristics of the principal compounds expected in the air stream from the groundwater treatment plant. Figure 1 shows the laboratory setup for these measurements. Based on a 1995 analysis of the volatile compounds extracted from the water, a surrogate mixture of TCE, DCE, and TCA (trichloroethane) was prepared. This mixture was treated with the laboratory-scale SDP cell to help establish field operating parameters for the mobile plasma processor. The surrogate gas-mixture composition was $6 \mathrm{ppm}$ of TCE, $0.3 \mathrm{ppm}$ of trans-1,2-DCE, and $0.3 \mathrm{ppm}$ of TCA in high-humidity (>90\%) air. The destruction and removal efficiency (DRE) of each component was measured as a function of plasma energy density using a gas chromatograph-mass spectrometer (GC/MS).

The results from these experiments are discussed further below in the section on experimental results. 


\section{Field Tests}

A schematic diagram of the field-test equipment setup is shown in Figure 2. A portion of the air stream exiting the water treatment facility sparger is directed to the SDPequipment influent port using two metal bellows pumps and a mass flow controller. This VOC-contaminated air stream then flows through the SDP cell banks, a dry scrubber, and a backup carbon filter before being vented to the atmosphere. The dry scrubber (filled with $13 \mathrm{X}$ molecular sieve) is used to collect effluent compounds, such as acids, which are a normal byproduct from the treatment of chlorocarbons in the SDP cells. The final carbon filter is included as a backup mechanism for capturing compounds that could be vented to the atmosphere, should the SDP equipment malfunction.

The SDP equipment is mounted in a trailer to allow it to be easily transported and, except for major electrical power, is a self-contained unit. A diagram showing the placement of equipment in the trailer is shown in Figure 3. A high-power, variable-frequency ( 100 to $2000 \mathrm{~Hz}$ ) power supply delivers up to $5 \mathrm{~kW}$ of power through a high-voltage step-up transformer to twenty planar SDP cells housed in a containment tank. Using this setup, process air flows up to 120 slpm could be obtained in the field tests. Thermal desorption tubes (TDTs) were used to capture the pollutants of concern for chemical analysis.

The degree of removal of contaminants in the air stream is mainly a function of the plasma energy density or specific energy, $\overline{\mathrm{E}}$, which is equal to the plasma power per unit gas flow. In these tests, the operating range of the system was varied from an energy density of $600 \mathrm{~J} / 1(1 \mathrm{~kW}$ at $100 \mathrm{slpm})$ to $7 \mathrm{~kJ} / \mathrm{l}(5 \mathrm{~kW}$ at $43 \mathrm{slpm})$. The operating frequency of the power supply $1500 \mathrm{~Hz}$ The SDP-cell temperature was kept constant at $35 \mathrm{C}$ by means of an oil-coolant-based heat exchanger.

Photographs of the equipment, taken during the tests at Tinker AFB, are shown in Figures 4-6. Figure 4 shows the mobile unit being driven into the water treatment facility building. Figure 5 presents an inside view of the plasma processing equipment, showing the power supply and SDP-cell containment tank. Figure 6 shows the dry scrubbers, the backup carbon absorber canisters, and another view of the power supply and containment tank.

Air contaminants were captured with thermal desorption tubes. An air sample was pulled through a TDT with a sampling pump using either the gas entering or exiting the SDP cells. Valves were used to switch between treated and untreated effluent. Various sensitivities were obtained by adjusting the flow rate through the TDT and the corresponding sampling time. The TDTs were then taken back to the laboratory at Los Alamos for analysis using a gas-chromatograph mass-spectrometer (GC/MS). Seventy tubes were used to obtain data at different energy densities to characterize the DRE's for SDP treatment of the effluent air stream. A TDT measurement matrix was established to obtain a series of data. For each energy density setting a set of four TDT's, two redundant sets of two different flows and sample times, were obtained for both the input and the output of the SDP cells. The test matrix was set up in this manner to allow for 
changes in the concentration of contaminants in the influent over the operating period (two days). The linear range of the TDT's are between 10 and $1000 \mathrm{ng}$ of absorbed material. Because we had no advanced knowledge of the concentrations of all contaminants in the effluent, various flow rates and sampling times were used in an attempt to keep the amount of absorbed material within the linear range of the tubes. The four conditions under which the TDTs were used are described below and will be referred to as $\mathrm{SC \# 1}$ through $\mathrm{SC} \# 4$ which stands for sample condition number one through four. For the untreated influent (highest concentrations of contaminants) samples were taken for 30 seconds at $100 \mathrm{sccm}$ (SC\#1) and for 2 minutes at $500 \mathrm{sccm}$ (SC\#2). With the SDP discharge energized (lower concentrations), samples were taken for 2 minutes at $500 \mathrm{sccm}(\mathrm{SC \# 3})$ and for 8 minutes at $500 \mathrm{sccm}$ (SC\#4).

\section{Experimental Results}

The experimental chemical results consist of two parts; laboratory measurements using surrogate gas mixtures and the data collected using the TDT's at the water treatment facility at Tinker AFB. Also an analysis of the liquid that was regenerated from the dry scrubber is described.

The key SDP scaling parameter, mentioned previously, is $\overline{\mathrm{E}}$. To increase the gas flow and maintain a fixed destruction ratio $[X] /[X]_{0}$, where $[X]$ is the resulting concentration and $[X]_{0}$ is the initial concentration, the power must be increased in proportion to the flow rate. To increase the destruction ratio $[\mathrm{X}] /[\mathrm{X}]_{0}$ for a given gas mixture, $\overline{\mathrm{E}}$ must be increased. This can be done by either increasing its power or decreasing its flow rate.

In ideal cases (when first-order chemistry dominates), the removal of a contaminant $X$ can be described by an exponential function

$$
[X]=[X]_{0} e^{(-\bar{E} / \beta)}
$$

where $\beta$ is the e-fold energy density. Supplying one $\beta$ of energy density to the reactor reduces the concentration by $1 / e$, two $\beta^{4}$ s reduces it by $1 / \mathrm{e}^{2}$, and so on. $\beta$ is given in base e units. For base ten units, the exponential function is replaced by powers of ten and $\beta$ by the ten-fold factor given by $\alpha=2.303 \beta$ so that,

$$
[X]=[X]_{0} 10^{(-\bar{E} / \alpha)}
$$

The number of "nines" removed (decades of removal) $\bar{E} / \alpha$ is described by the equation,

$$
\tilde{\mathrm{E}} / \alpha=-\log \left([\mathrm{X}] /[\mathrm{X}]_{0}\right)
$$

In base ten units, the fractional removal, $1-\left([\mathrm{X}] /[\mathrm{X}]_{0}\right)$, is often expressed in terms of a DRE of so many decades removed; e.g., three decades removed, $\bar{E} / \alpha=3$, (or $99.9 \%$ 
DRE) is achieved by supplying the reactor with three ten-fold E's (three $\alpha$ 's). For real cases, the removal expression is not necessarily an ideal exponential, so the use of the $\alpha$ and $\beta$-values are only approximations. Nevertheless, it is still quite useful over a limited range of e-folds. The $\alpha$ and $\beta$-values for representative compounds are usually determined by laboratory experiments.

\section{Laboratory Measurements}

A benchtop SDP cell and GC/MS analytical diagnostics were used to test the destruction of the surrogate TCE, DCE, and TCA gas mixture as a function of plasma energy density. DRE values for individual compounds were determined by comparing pollutant concentrations measured with the SDP cell energized to those measured with the cell power off. Based on the analysis of the contaminated air stream at the water treatment facility in 1995, a surrogate gas mixture was used in a laboratory-scale SDP cell at LANL with a composition of $6 \mathrm{ppm}$ TCE, and $0.3 \mathrm{ppm}$ of both TCA and trans-1,2-DCE in highhumidity (greater than $90 \%$ ) air. The DRE of the components were measured versus energy density using a GC/MS. The results from this experiment are shown in Fig. 7 and Table I, where for the lowest energy density used $(750 \mathrm{~J} / \mathrm{l}), \mathrm{DCE}$ was below the detection limit of the GC/MS which was estimated at $40 \mathrm{ppb}$. Therefore a precise DRE for DCE was not possible but was greater than $87 \%$ at $750 \mathrm{~J} / \mathrm{l}$. The DRE for TCE was better than two "nines", $99.2 \%$ at $750 \mathrm{~J} / 1$, which gives the values $\alpha=350 \mathrm{~J} / 1$ and $\beta=150 \mathrm{~J} / \mathrm{l}$. For TCA the energy density versus decades removed gives the values $\alpha=10 \mathrm{~kJ} / \mathrm{l}$ and $\beta=4.3 \mathrm{~kJ} / \mathrm{l}$. It should be noted that at Tinker AFB no TCA was detected in the water treatment facility effluent.

Table I. Decadic specific energies for both laboratory and field experiments.

\begin{tabular}{|l|c|c|}
\hline \multicolumn{1}{|c|}{ Compound } & $\begin{array}{c}\text { Laboratory } \\
\alpha(\mathrm{J} / \mathrm{l})\end{array}$ & $\begin{array}{c}\text { Field } \\
\alpha(\mathrm{J} / \mathrm{l})\end{array}$ \\
\hline TCE & 350 & 300 \\
\hline cis-1,2-DCE & -- & 300 \\
\hline PCE (dry) & 280 & -- \\
\hline PCE (humid) & 4200 & 700 \\
\hline
\end{tabular}

Even through no TCA was detected in the effluent stream at Tinker AFB, perchloroethene (PCE) was detected at a concentration of approximately $0.2 \mathrm{ppm}$. A follow up experiment was completed at Los Alamos using $100 \mathrm{ppm}$ of PCE in wet $(75 \%$ relative humidity) and dry air and the results are shown in Fig. 8. In dry air, the values for $\alpha$ and $\beta$ were $280 \mathrm{~J} / 1$ and $120 \mathrm{~J} / 1$ respectively. In wet air the values for $\alpha$ and $\beta$ were $4.2 \mathrm{~kJ} / \mathrm{l}$ and $1.8 \mathrm{~kJ} / \mathrm{l}$ respectively. This is one of the highest differences in DRE when comparing a dry versus wet surrogate mixture yet seen in the laboratory. 


\section{Tinker AFB Field Measurements}

The measurements at Tinker AFB were carried out over a period of two days, with three days of setup and take down time. A plot of the untreated concentrations of the highest contaminant components versus TDT sample number is shown in Fig. 9. Since the tube numbers were evenly distributed throughout the two days of measurements, the plot also represents the concentrations versus time. TCE had the highest concentration at 5 to $6 \mathrm{ppm}$ and PCE had the lowest concentration at 0.15 to $0.3 \mathrm{ppm}$. Since the input concentration, $[\mathrm{X}]_{0}$, did vary with time for these compounds, the DRE was calculated using the values of $[\mathrm{X}]_{0}$ and $[\mathrm{X}]$ as close together in time as possible.

Out of the many contaminants in the influent stream it was possible to plot the DRE versus energy density for only three compounds as shown in Fig. 10. As stated above different sample times and flows were used to keep the measured contaminant concentrations within the linear range of the TDT's. Of the two flow/time conditions of the samples taken from the inlet to the SDP system, only SC\#1 was within the linear range of the TDTs. The samples taken at the output of the energized SDP system using both flow conditions, $\mathrm{SC \#} 3$ and $\mathrm{SCH} 4$, were within the linear range of the TDTs. Because of this, two DRE plots were obtained for each compound based on the ratios of SC\#3/SC\#1 and SC\#4/SC\#1. As can be seen in Fig. 10, the SC\#3/SC\#1 (8 minute sample duration) gave slightly higher DRE's than the SC\#4/SC\#1 (2 minute sample duration). This can be attributed to the fact that the 8 minute sample time will absorb more material and therefore be at the high end of the linear range of the TDT's while the 2 minute sample time will be at the lower end of the linear range of the TDT's. Because of the difference in the ranges of sample mass collected using the two sampling conditions, it is not surprising that an offset in the data was produced because the absorption rate is not perfectly linear.

A better representation of the DRE versus energy density is given by taking the average of the data in Fig. 10, which is plotted in Fig. 11. The limits of the linear range of the measurement in decades removed for each compound are 3.6 for TCE, 2.7 for cis-1,2DCE, and 1.9 for PCE. Because of these limits and the fewer data points available, the points at $3 \mathrm{~kJ} / \mathrm{l}$ are shaded to indicate that they may be less reliable. As seen in Fig. 11, the DRE's for TCE and PCE increase with energy density, while that of cis-1,2-DCE has a minimum at $1.2 \mathrm{~kJ} / \mathrm{l}$. One possible explanation may be that cis-1,2-DCE is a byproduct of a reaction from another contaminant at $1.2 \mathrm{~kJ} / 1$. Because of this effect, cis-1,2-DCE would require additional energy to achieve a higher DRE. However, it should be noted that all values of DRE are above $90 \%$ at $600 \mathrm{~J} / \mathrm{l}$, with the exception of PCE which has a DRE of $87 \%$. The estimated values of $\alpha$ and $\beta$ are as follows: TCE and cis-1,2-DCE gave $\alpha=300 \mathrm{~J} / 1$ and $\beta=130 \mathrm{~J} / 1$; and PCE gave $\alpha=700 \mathrm{~J} / 1$ and $\beta=300 \mathrm{~J} / 1$. The values for $\alpha$ and $\beta$ for TCE are similar to those measured in the laboratory (refer to Table I). However, the values for $\alpha$ and $\beta$ were considerably less for PCE in the field demonstration compared to the laboratory results. An explanation for this is not readily available, although increased DREs have been observed in other field demonstrations. Typical differences between laboratory and field conditions which may play a part in this 
effect include higher SDP system temperatures in the field, different contaminant concentrations in the field, and the presence of many more contaminant compounds in field demonstrations.

Most of the components in the influent gas stream fell below the resolution of the TDT's at $600 \mathrm{~J} / 1$ in the SDP system. The starting concentration for toluene was approximately $1.4 \mathrm{ppm}$ and fell below the 1 to $2 \mathrm{ppb}$ resolution limit of the TDTs at $600 \mathrm{~J} / 1$ in the SDP system. This indicates that even though an exact DRE cannot be calculated for toluene, the DRE for toluene was greater than $99.6 \%$ at $600 \mathrm{~J} / 1$. A similar analysis can be made for the xylenes in the influent where the DRE was greater than $97 \%$ at $600 \mathrm{~J} / \mathrm{l}$ with a starting concentration of approximately $180 \mathrm{ppb}$. Other contaminant components in the influent stream were in small concentrations (less than $70 \mathrm{ppb}$ ) and also fell below the resolution of the TDT diagnostic technique at the lowest energy density used in the SDP system. The contaminant components in this category are: vinyl chloride, 1,1-dichloroethene, trans-1,2-dichloroethene, methyl-ethyl-ketone, 1,2-dichloroethane, benzene, 4, methyl2,pentanone, ethyl benzene, trimethyl benzene, and dichlorobenze.

Four components were identified as compounds inherent in the TDT diagnostic method: chloromethane, bromomethane, methylene chloride, and acetone. Chloromethane, bromomethane, and methylene chloride showed no trend with energy density in the SDP system and had a large variation in background level throughout the analyzed data. However, acetone was also measured as a component in the influent gas stream in addition to being a compound inherent in the TDT diagnostic method. An analysis of a blank TDT tube, which had never been used, produced $66 \mathrm{ng}$ of acetone. It was expected that the amount of acetone in the background varies as much as that listed above throughout the data. However, using $70 \mathrm{ng}$ as a reference for a background acetone level, the concentration of acetone versus energy density is plotted in Fig. 12, where the shaded area represents the region of probable interference from the background level. From this it is seen that the acetone is reduced as a function of energy density; although, a precise number for the DRE is unclear.

Three constituents (carbon tetrachloride, chloroform, and chloroethane) that are not present in the influent gas stream appear to be produced in the system. The concentration versus energy density of the compounds are plotted in Fig. 13. Chloroethane is present only at low energies and is destroyed at higher energy densities up to $7 \mathrm{~kJ} / \mathrm{l}$. Therefore, chloroethane may be a byproduct of some other component. Both chloroform and carbon tetrachloride increase with energy density. If these were true byproducts, it could be expected that chloroform and carbon tetrachloride would have been measured as byproducts in the laboratory experiments (see Figures 7 and 8). However, a byproduct, analysis of the data in Figures 7 and 8 did not produce measurable amounts of chloroform, carbon tetrachloride, or chloroethane. A chlorine balance is one method commonly used to verify the conversion of initial compounds into resulting compounds. In this case, the remaining measurable influent compounds (PCE, TCE, and cis-1,2-DCE) tested at higher energy densities could not supply the increasing amounts of chlorine necessary to provide the increasing amounts of chloroform and carbon tetrachloride. 
Unfortunately, the other chlorinated compounds, such as hydrochloric acid, were not measured and a link between these other compounds and chloroform and carbon tetrachloride is unclear. Therefore, based on what we know at this point, we cannot conclude if these components are byproducts produced in the SDP cells or whether they are a product of the TDT diagnostic apparatus.

Finally, in previous experiments with xylene and toluene, a carbon-based residue (presumably a polymer) has been observed as deposits in the glass-lined SDP cells. A buildup in the cells would ultimately limit the useful lifetime of an SDP system. However, a similar residue was not observed in these cells after disassembly. The reason for this is not clear, although previous experiments have shown that oxygen-rich environments produce less carbon buildup. Also the starting concentrations of xylene and toluene were small, which may aid in reducing this effect.

\section{Dry Scrubber Regeneration}

As shown in Figures 2 and 3, a dry scrubber, consisting of two cylinders filled with molecular-sieve pellets was used to collect the byproducts of the SDP system. After the return of the SDP equipment to Los Alamos, the dry scrubber cylinders were regenerated. In the regeneration process, a small pump is used to flow gas through the molecular-sieve filled cylinders in a closed-loop system. The gas flows through the cylinders filled with molecular sieve (which are heated to $100 \mathrm{C}$ ) then through a cold trap (which is cooled to $-30 \mathrm{C}$ ). The vapors produced in the heated dry scrubber cylinders are collected in the cold trap. The relative humidity is monitored in the gas flow and the system is considered to be fully regenerated when the relative humidity falls close to zero.

Approximately two liters of liquid were collected from the regenerated dry scrubber and analyzed for acid content. The results of the analysis are: [nitrite $/$ itrate] $=1.01 \mathrm{~g} / \mathrm{l}$, [chloride] $=32 \mathrm{mg} / \mathrm{l}$, [sulfate] $=9 \mathrm{mg} / \mathrm{l}$, and no detectable levels of fluoride. The high concentrations of nitric acid collected were consistent with other SDP systems since $\mathrm{NO}_{X}$ can be produced in the discharge and form nitric acid in a humid air stream. The small amount of chloride collected was consistent with the low levels of chlorinated compounds (a few ppm or less) in the influent air stream. Since there were no fluorinated compounds measured in the influent, it was expected that no fluoride ions would be detected in the regeneration liquid. Since there were no known sources of sulfur contamination in the SDP system, the most likely source of the sulfate was from the groundwater itself. As a final step, these acids could be neutralized, thus making disposal easier.

\section{Conclusion and Summary}

The combined SDP/dry-scrubber system was used to demonstrate the applicability of NTP treatment to the effluent containing low-concentration VOC's from a groundwater treatment facility. This technology shows promise as a polishing stage for such a treatment facility. NTP's have the advantage of producing byproducts such as acids that can be reclaimed from the dry scrubber for simple disposal. 
This demonstration has shown that for an energy density of $600 \mathrm{~J} / 1$ (power/flow of $0.3 \mathrm{~kW} / \mathrm{cfm}$ ) all contaminants with the exception of PCE ( $87 \%$ DRE) had DREs of greater than $90 \%$. Since the starting concentrations of the principal contaminants were less than $10 \mathrm{ppm}$, the degree of removal required to meet emission standards may be low. Therefore, in a practical system, a lower energy density can probably be employed. The only byproducts that seem to increase with energy density were chloroform, carbon tetrachloride, and chloroethane (whose typical concentrations are only 10-50 ppb). However, it is still uncertain whether this is an artifact of the TDT chemical diagnostic method or whether these are true byproducts produced in the SDP system. Also no carbon-based residues, which might limit the operational lifetime of the system, were observed in the cells. The dry scrubber produced an acidic water solution after regeneration, which makes disposal easier than disposal of water laden with solvents.

\section{References}

1. B.M. Penetrante and S.E. Schultheis, editors, Non-Thermal Plasma Techniques for Pollution Control, Springer-Verlag, NATO ASI Series, Vol. G34, Parts A \& B, 1993.

2. B. Eliasson and U. Kogelschatz, "Nonequilibrium Volume Plasma Chemical Processing," IEEE Transaction on Plasma Science, Vol. 19, No. 6, 1063-1077, 1991.

3. L.A. Rosocha, J.J. Coogan, R.A. Korzekwa, D.A. Secker, R.F. Reimers, P.G. Herrmann, P.J. Chase, M.P. Gross, and M.R. Jones, "Field Demonstration and Commercialization of Silent Discharge Plasma Air Pollutant Control Technology," 2nd International Conference on Environmental Applications of Advanced Oxidation Technologies, San Francisco, CA, February 28 - March 1, 1996.

\section{Acknowledgment}

The work described in this report was supported under a cooperative Research and Development Agreement (CRADA \# LA93C10100) between the Los Alamos National Laboratory (LANL) and the Electric Power Research Institute (EPRI). LANL is operated for the United States Department of Energy (DOE) by the University of California under contract \# W-7405-ENG36. The authors would like to thank Myron Jones, the EPRI program manager, the DOE, and LANL for their support under the CRADA.

The authors are also highly appreciate of the assistance of Tinker Air Force Base (especially Thomas Walker and Allen Lawrence, of the Tinker Environmental Directorate) in providing enthusiasm as well as logistical and field support for this demonstration. 


\section{Figure Captions}

Figure 1. The laboratory experimental arrangement showing the gas flow controlling equipment, the premixed cylinders, the SDP cells, and chemical sampling equipment.

Figure 2. The field test experimental arrangement showing the gas flow controlling equipment, the SDP cells, chemical sampling equipment, dry scrubber, and carbon filters.

Figure 3. The placement of SDP equipment in the trailer used at Tinker AFB.

Figure 4. Photograph of mobile SDP processor as it was being driven into the building which houses the water treatment facility.

Figure 5. An inside view of the plasma processing equipment, showing the power supply on the left and the SDP-cell containment tank on the right.

Figure 6. Photograph showing the dry scrubbers and backup carbon absorber canisters in the left foreground, the power supply in the right foreground, and another view of the containment tank in the left background.

Figure 7. The energy density, $\overrightarrow{\mathrm{E}}$, versus decades removed for the laboratory measurement of the surrogate gas mixture containing $6 \mathrm{ppm}$ of TCE, $0.3 \mathrm{ppm}$ of TCA and $0.3 \mathrm{ppm}$ of trans-1,2-DCE.

Figure 8 . The energy density, $\overline{\mathrm{E}}$, versus decades removed for the laboratory measurement of the surrogate gas mixture containing $100 \mathrm{ppm}$ of PCE for both dry and wet air.

Figure 9. The concentration versus sample tube number and operation time of the four highest concentration contaminants in the water treatment facility effluent.

Figure 10. The energy density, $\overline{\mathrm{E}}$, versus decades removed for the field measurement of the water treatment facility effluent for TCE, cis-1,2-DCE, and PCE, where the shaded symbols represents the 2 minute sampling duration and the open symbols represent the 8 minute sampling duration.

Figure 11. The energy density, $\overline{\mathrm{E}}$, versus decades removed for the field measurement of the water treatment facility effluent for the averaged values of TCE, cis-1,2DCE, and PCE. 
Figure 12. The energy density, $\overline{\mathrm{E}}$, versus acetone concentration for the field measurement of the water treatment facility effluent, where the shaded area represents the region of interference of the amount of acetone inherent in the TDT diagnostic method.

Figure 13. The energy density, $\overline{\mathrm{E}}$, versus concentration for the field measurement of the water treatment facility effluent for chloroethane, chloroform, and carbon tetrachloride. 


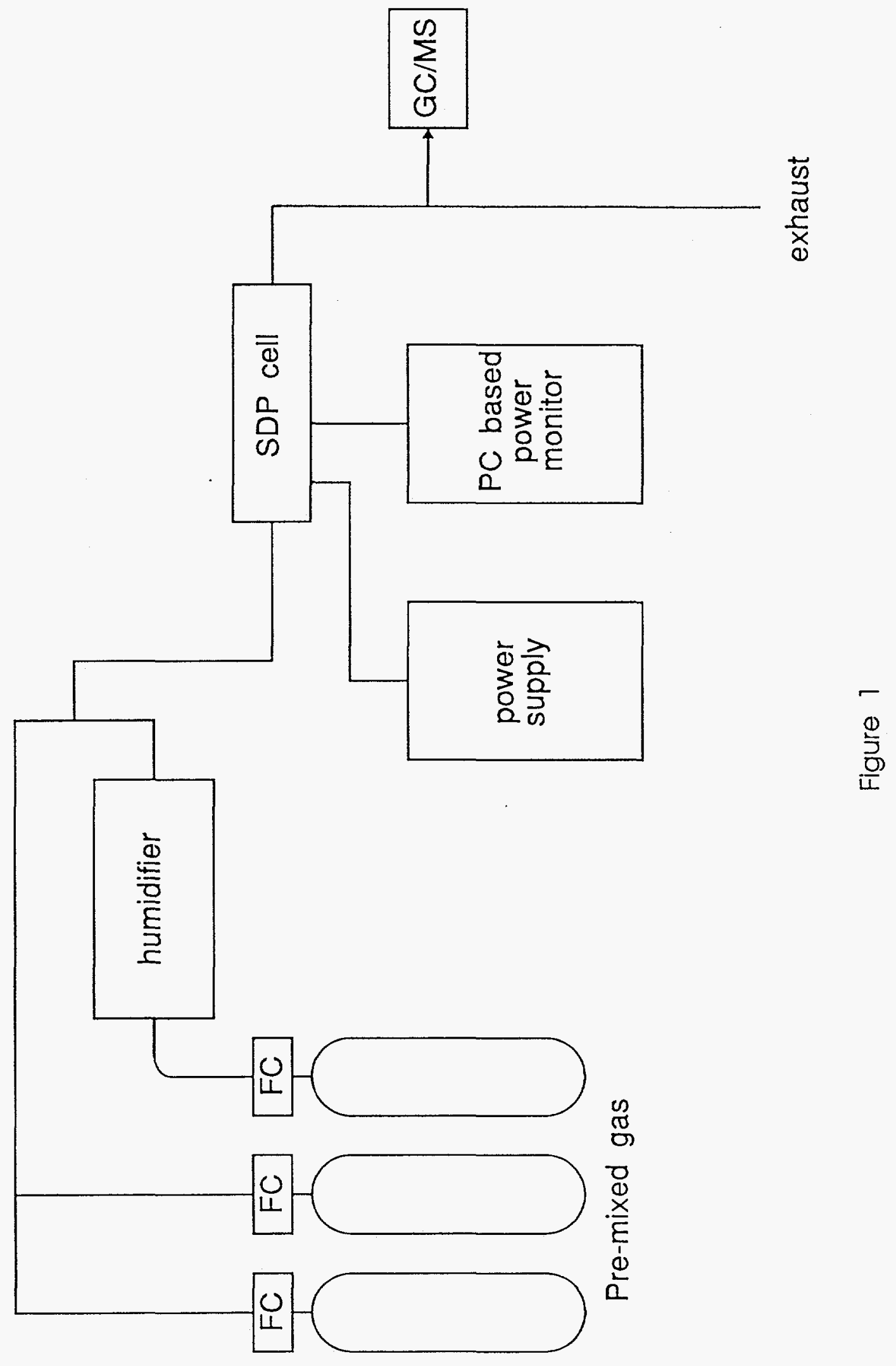




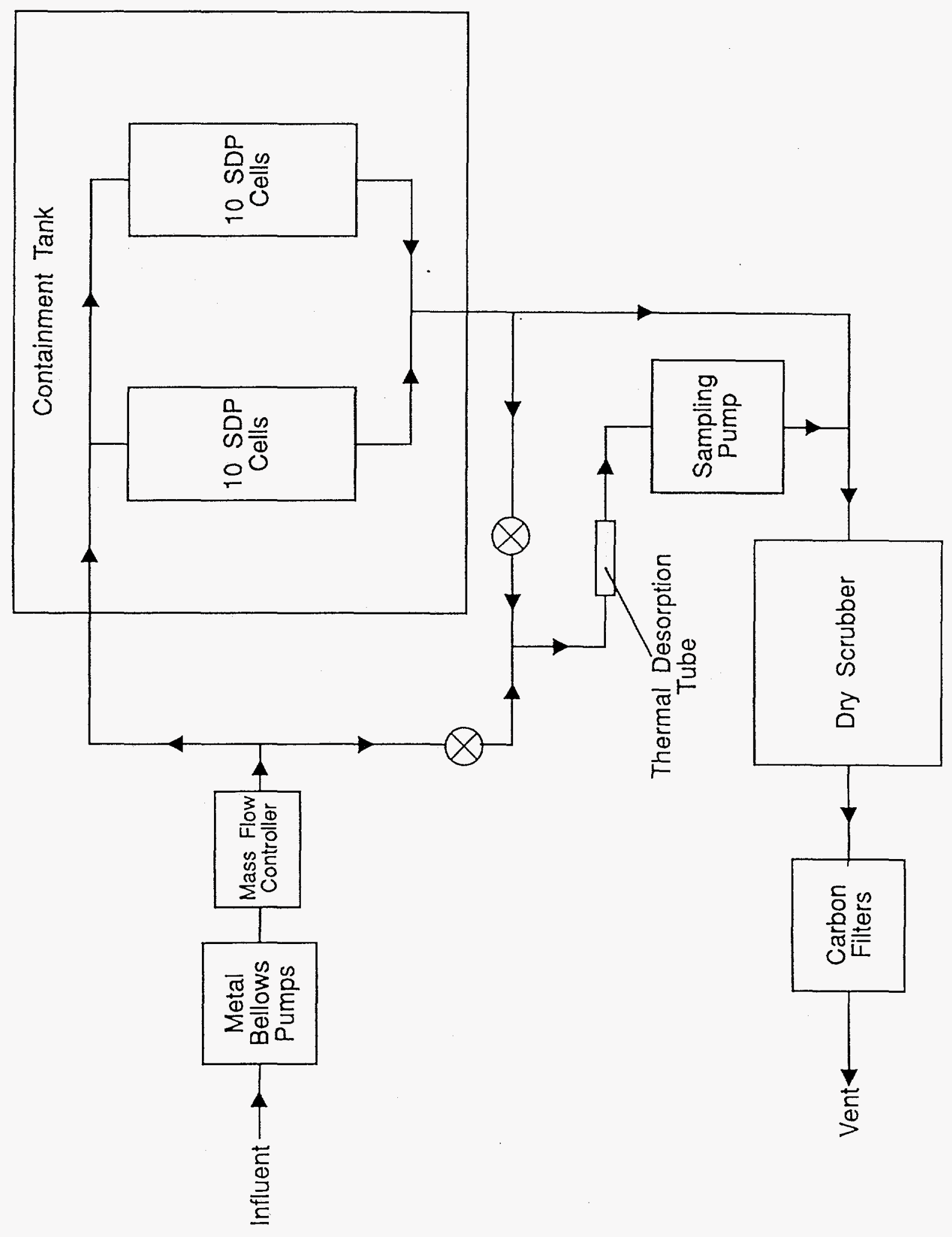




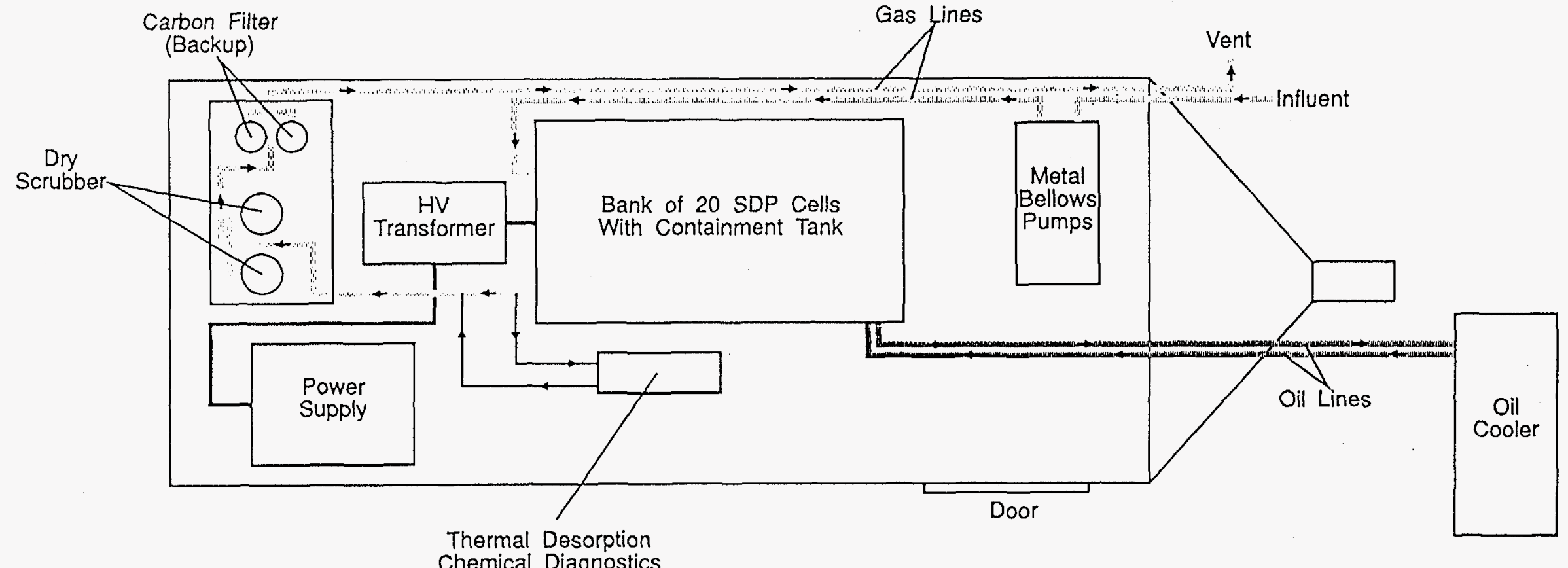

Figure 3 


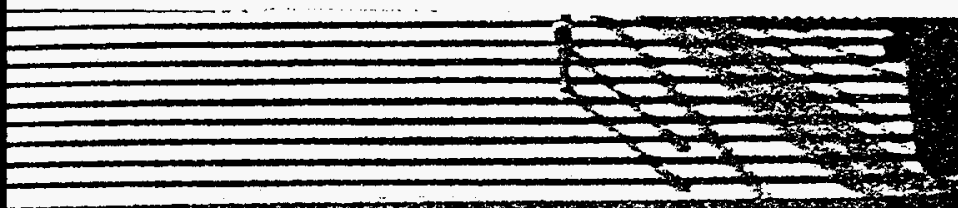

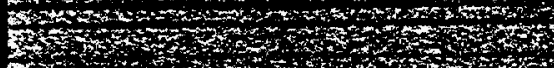

3.

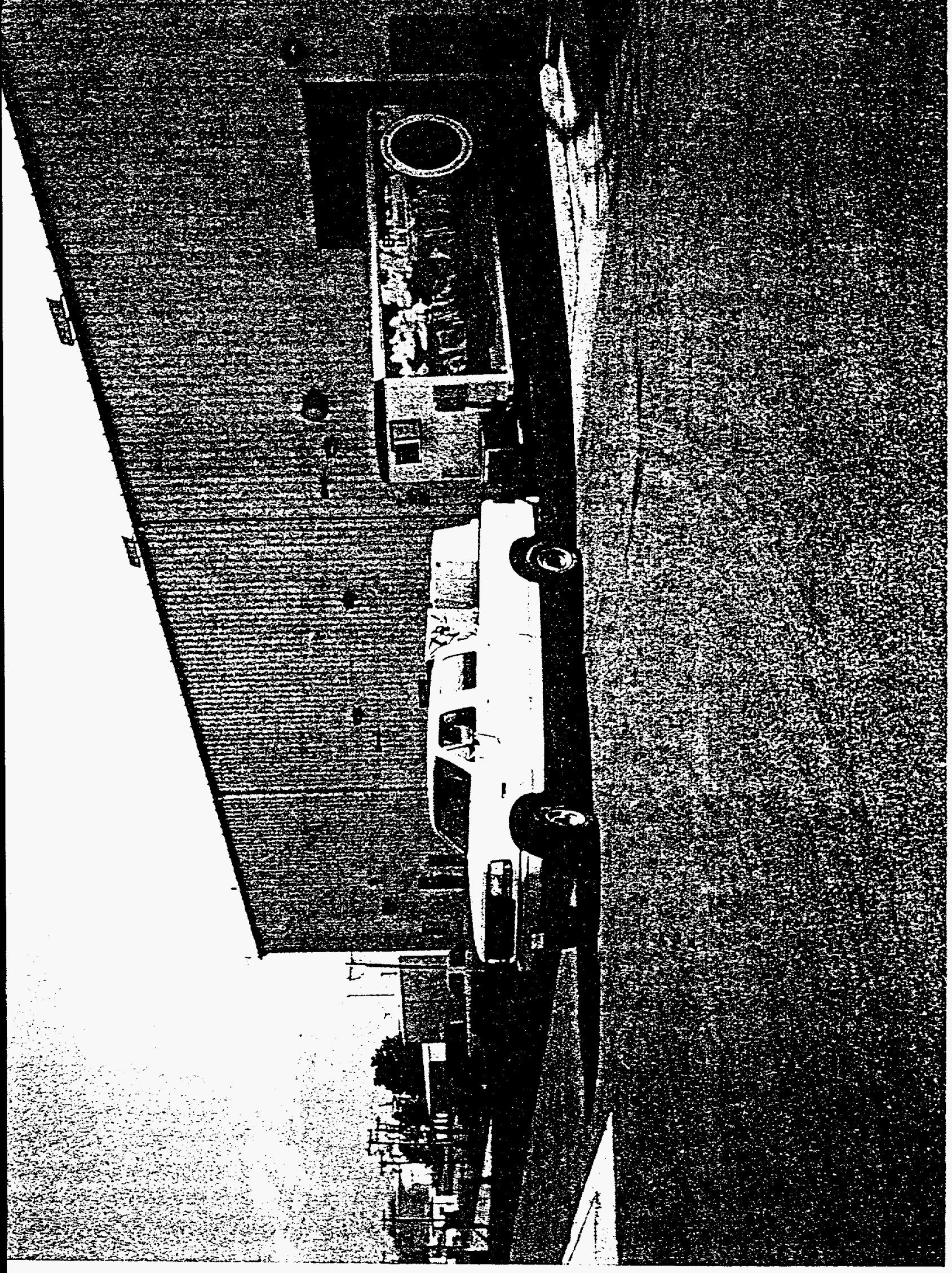




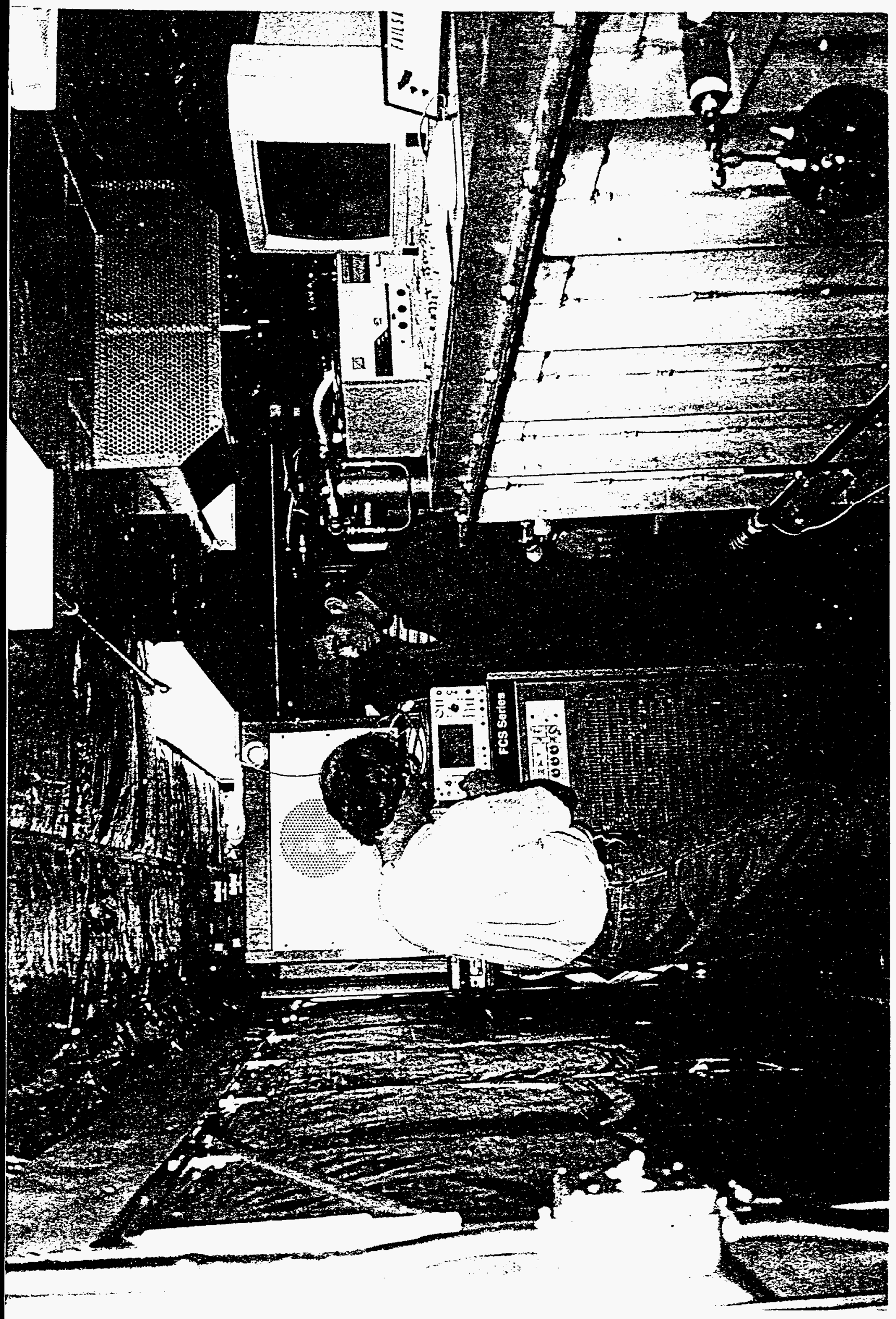




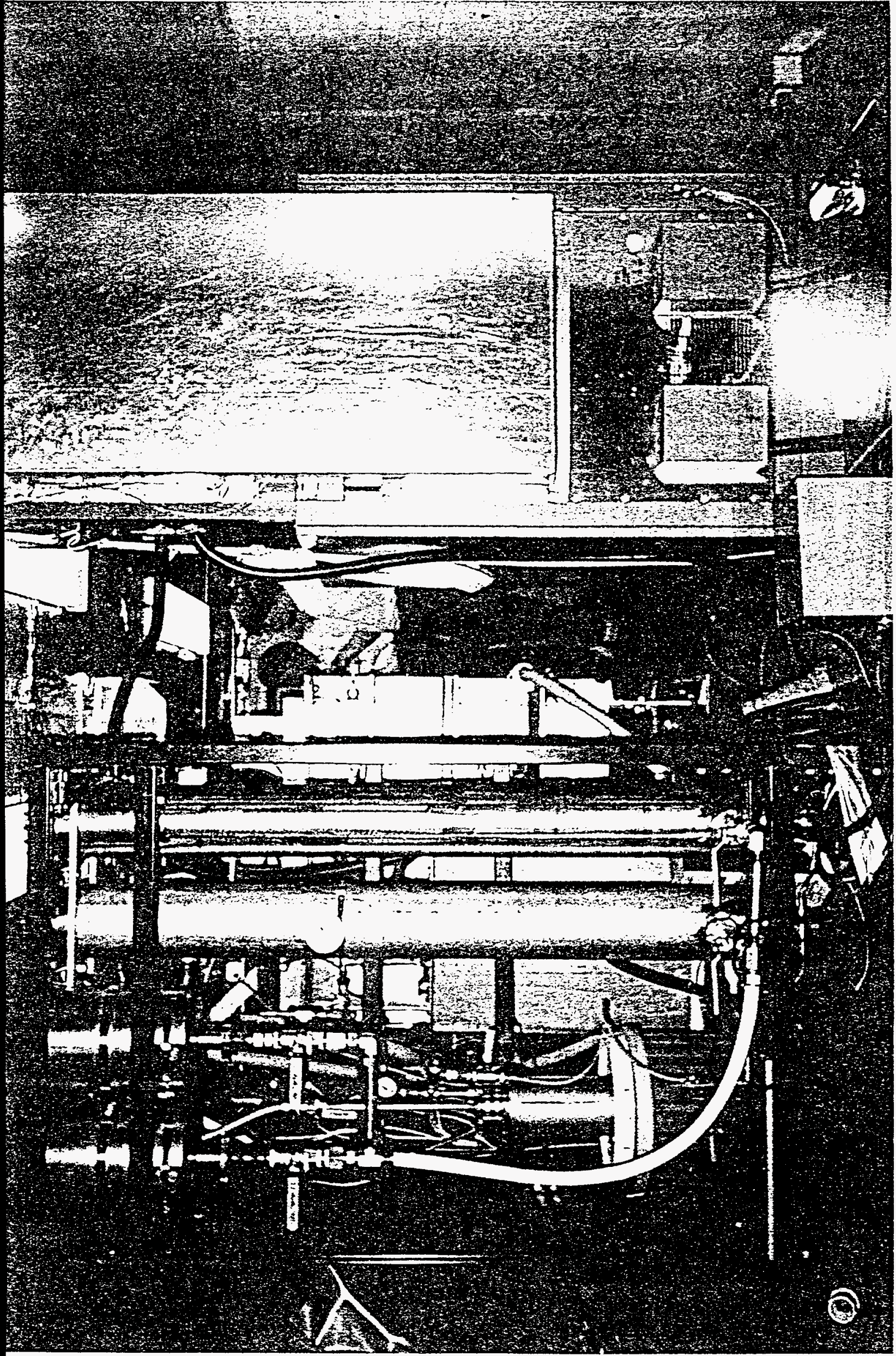




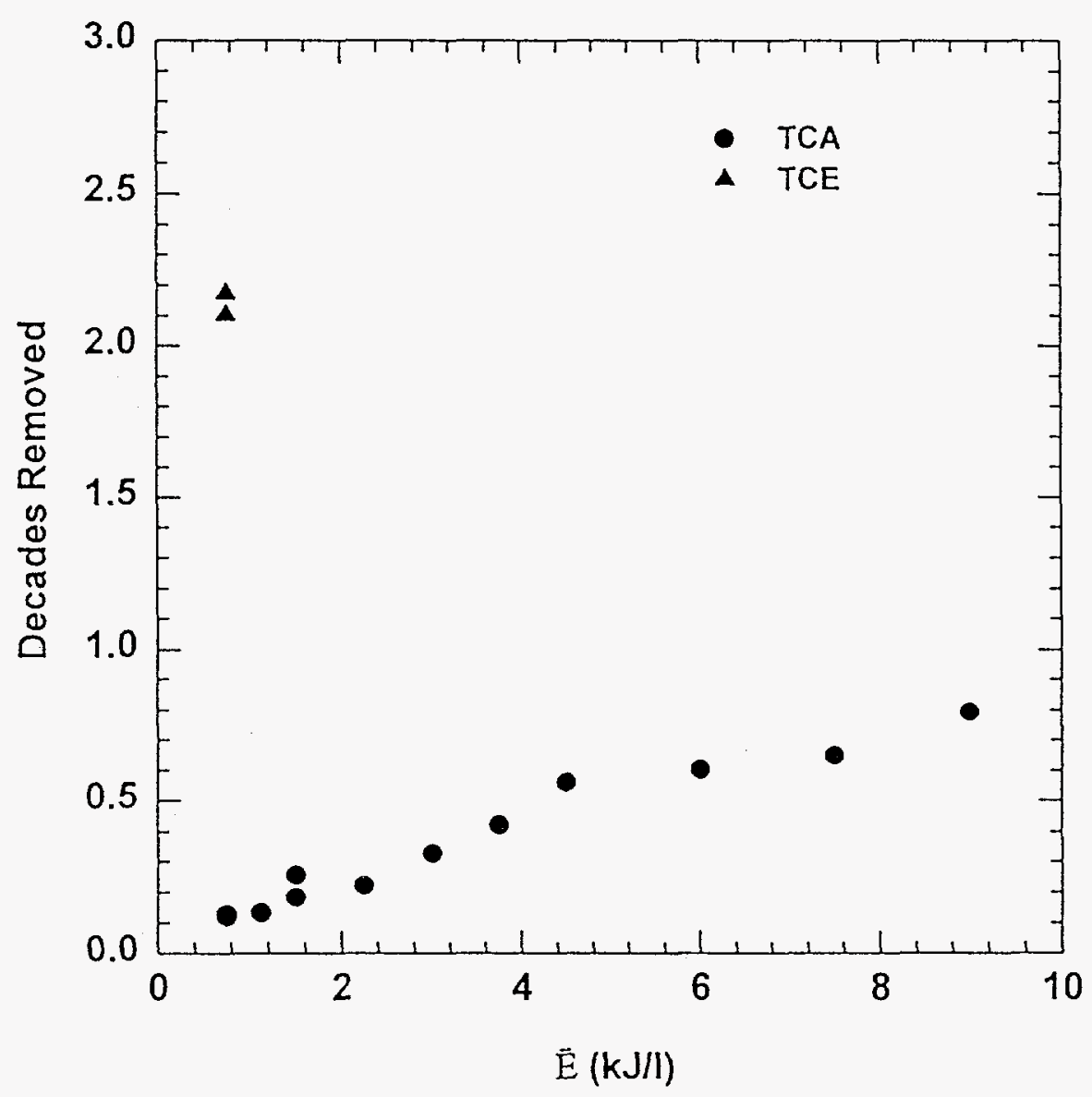

Figure 7 


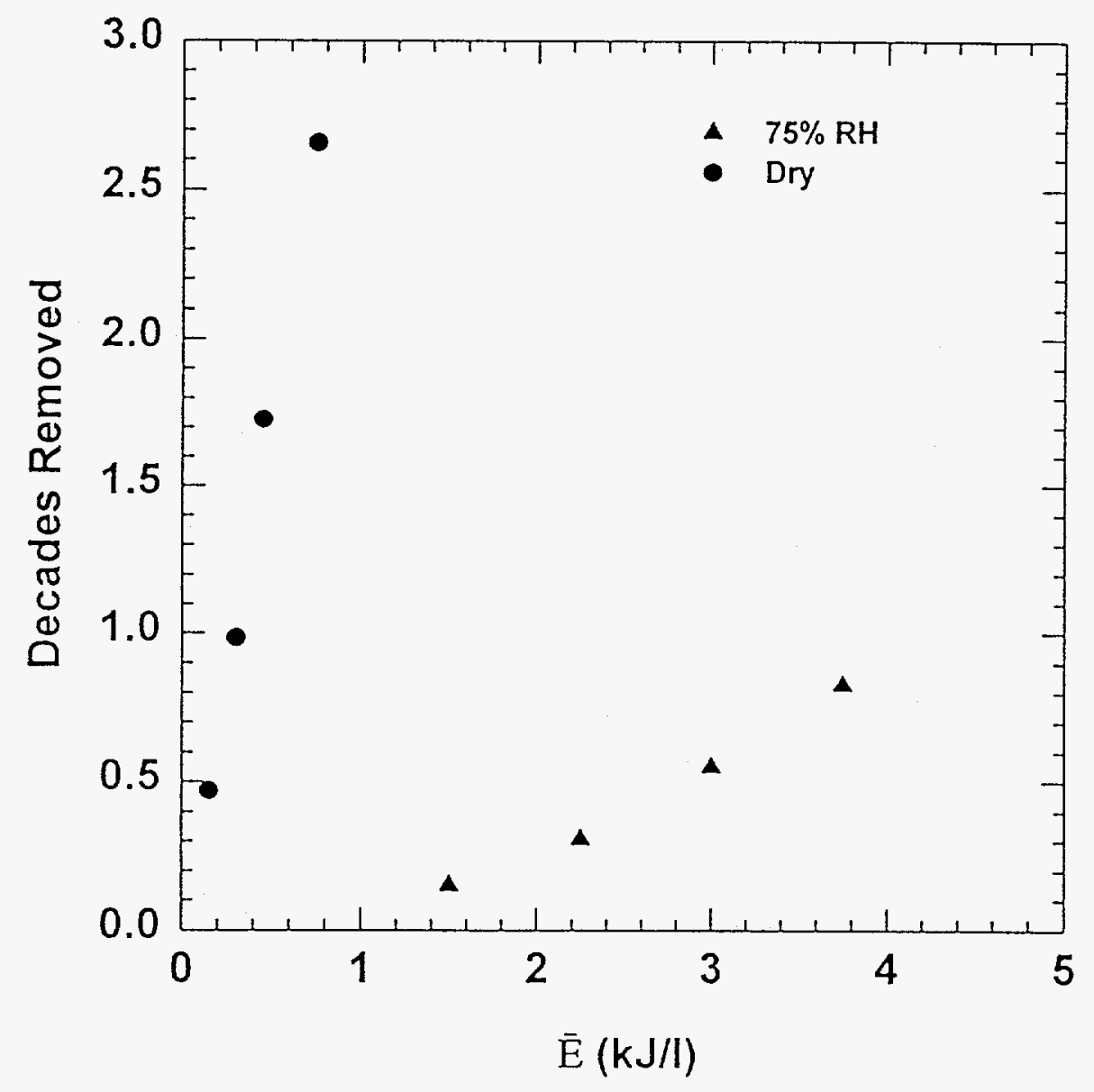

Figure 8 


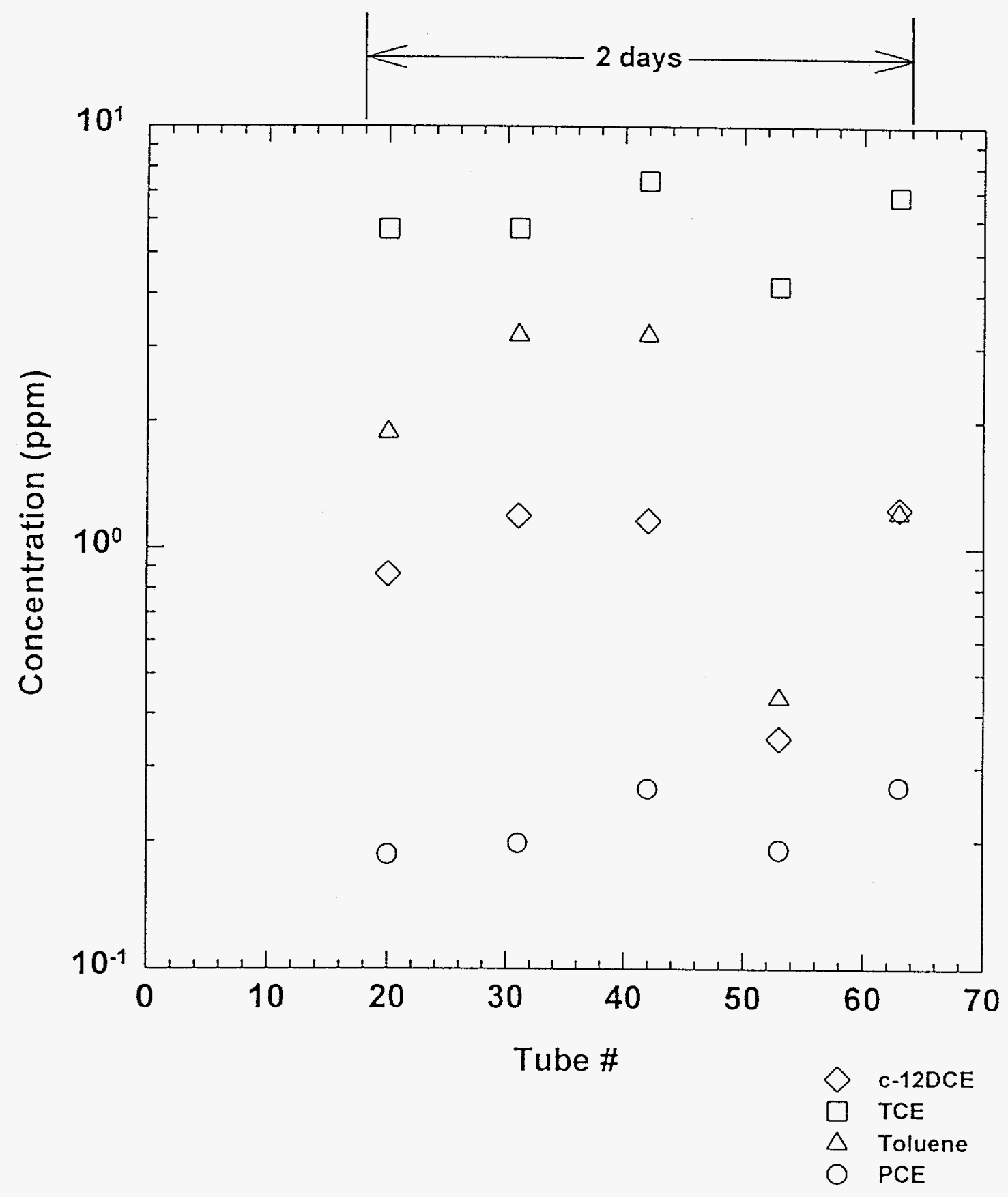

Figure 9 

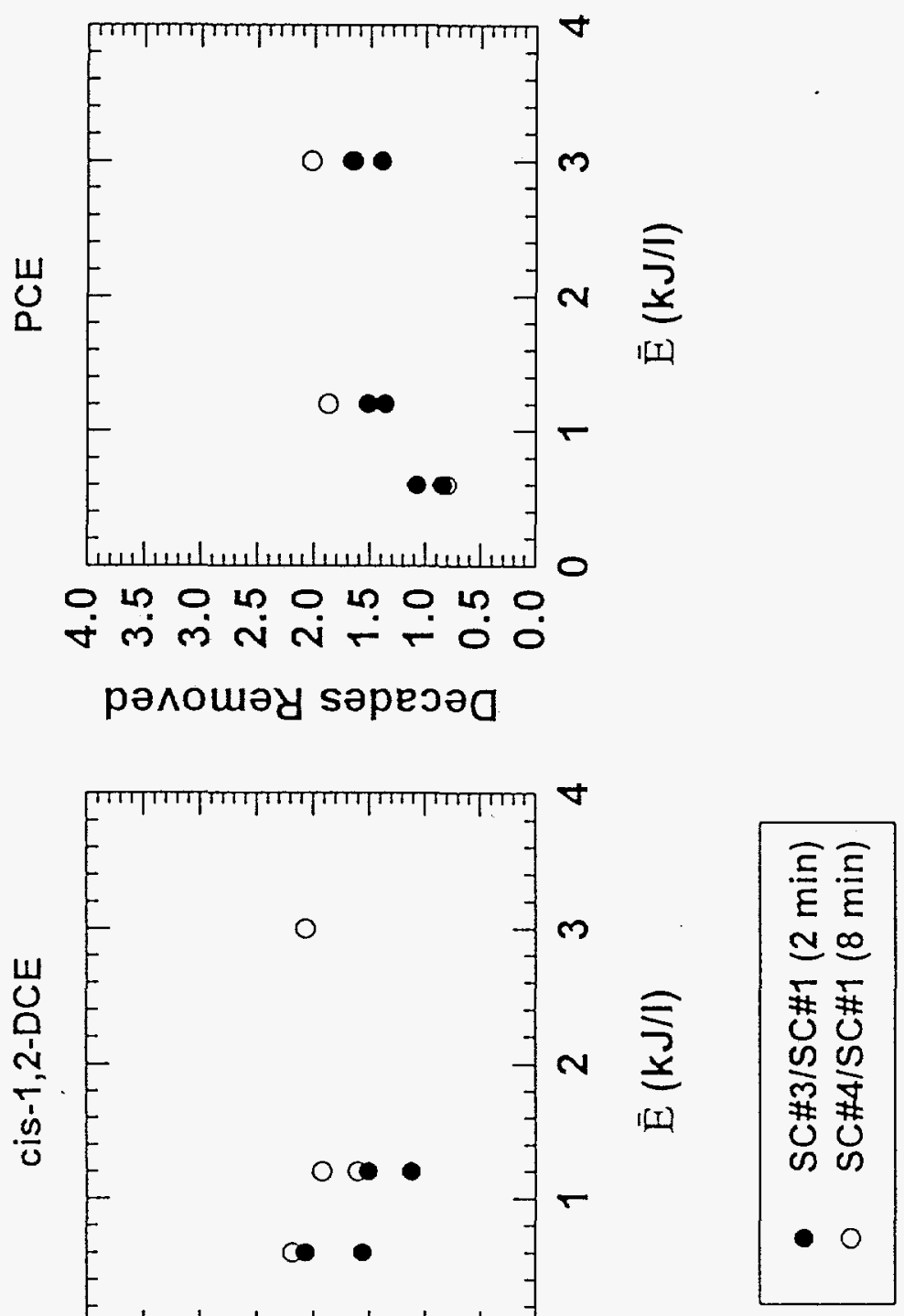

은

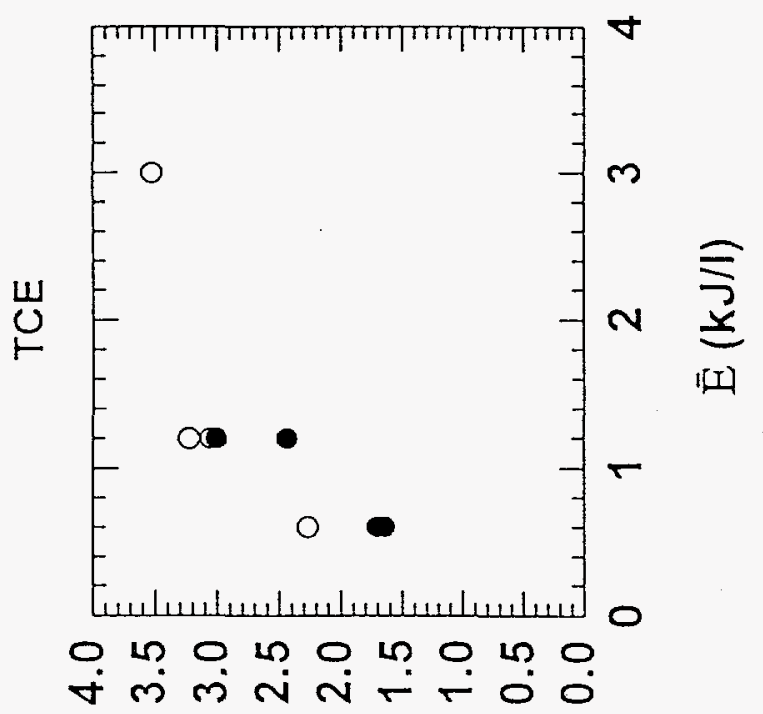

рәлошәу sәреэә 


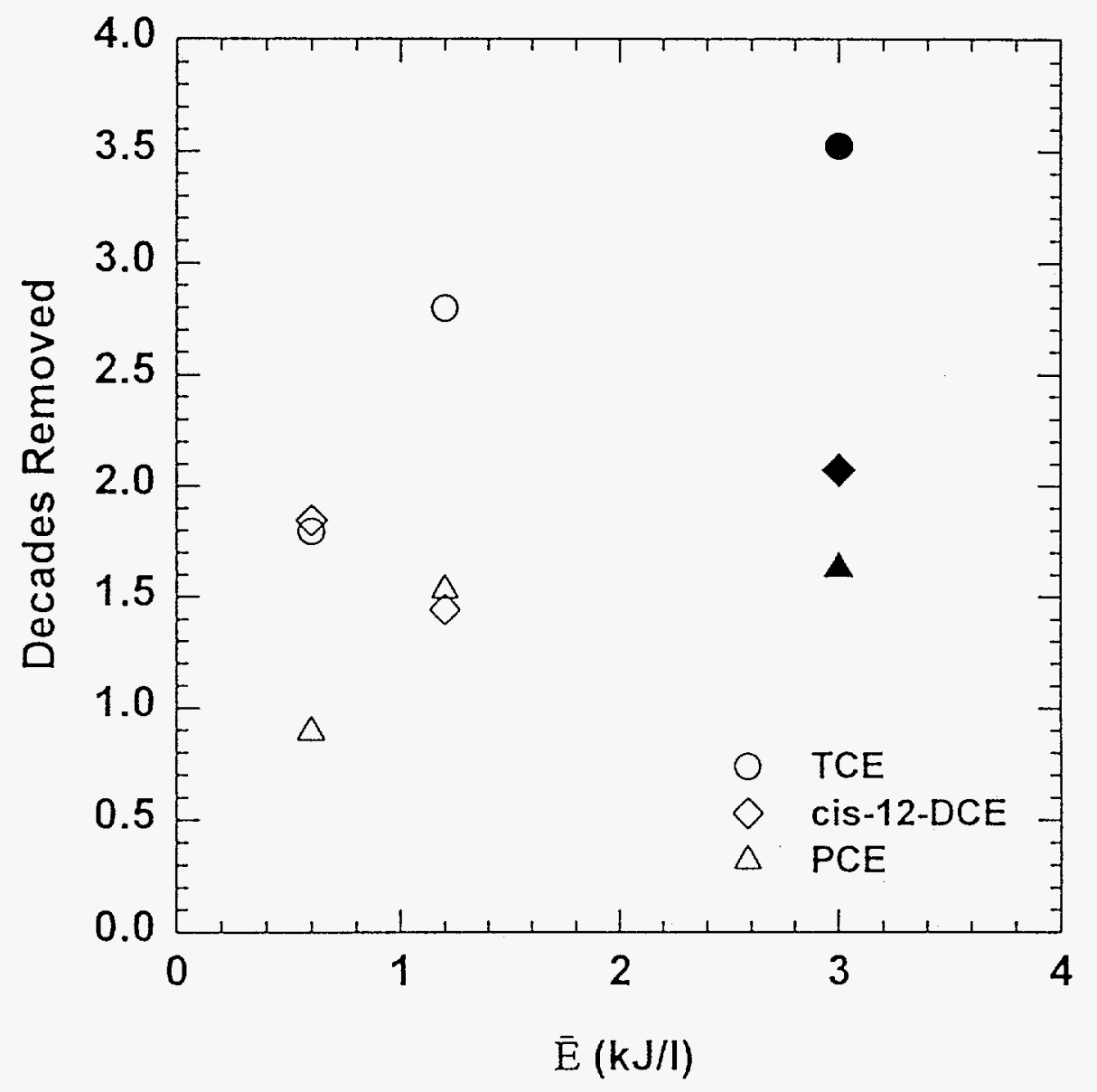

Figure 11 


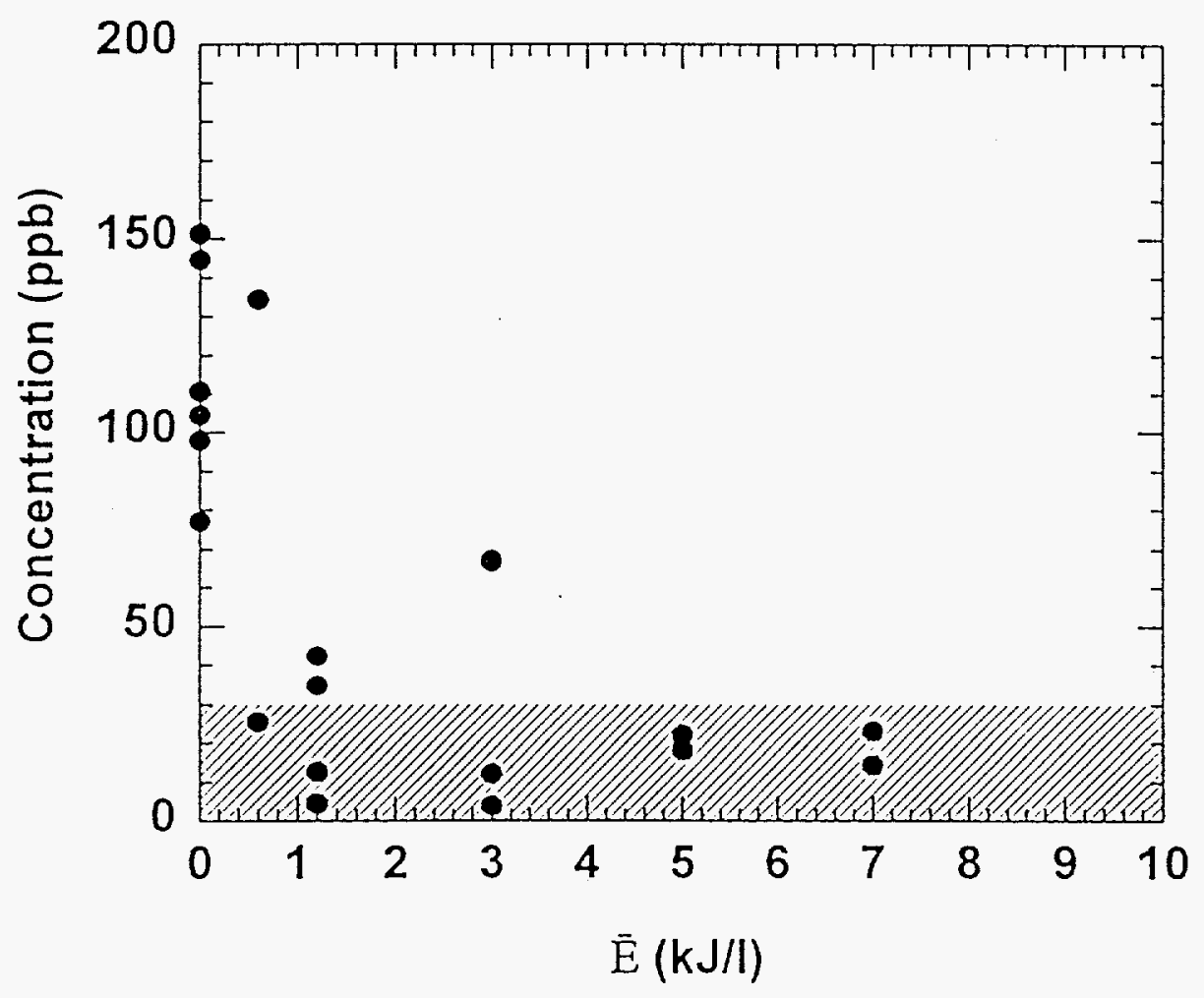

Figure 12 

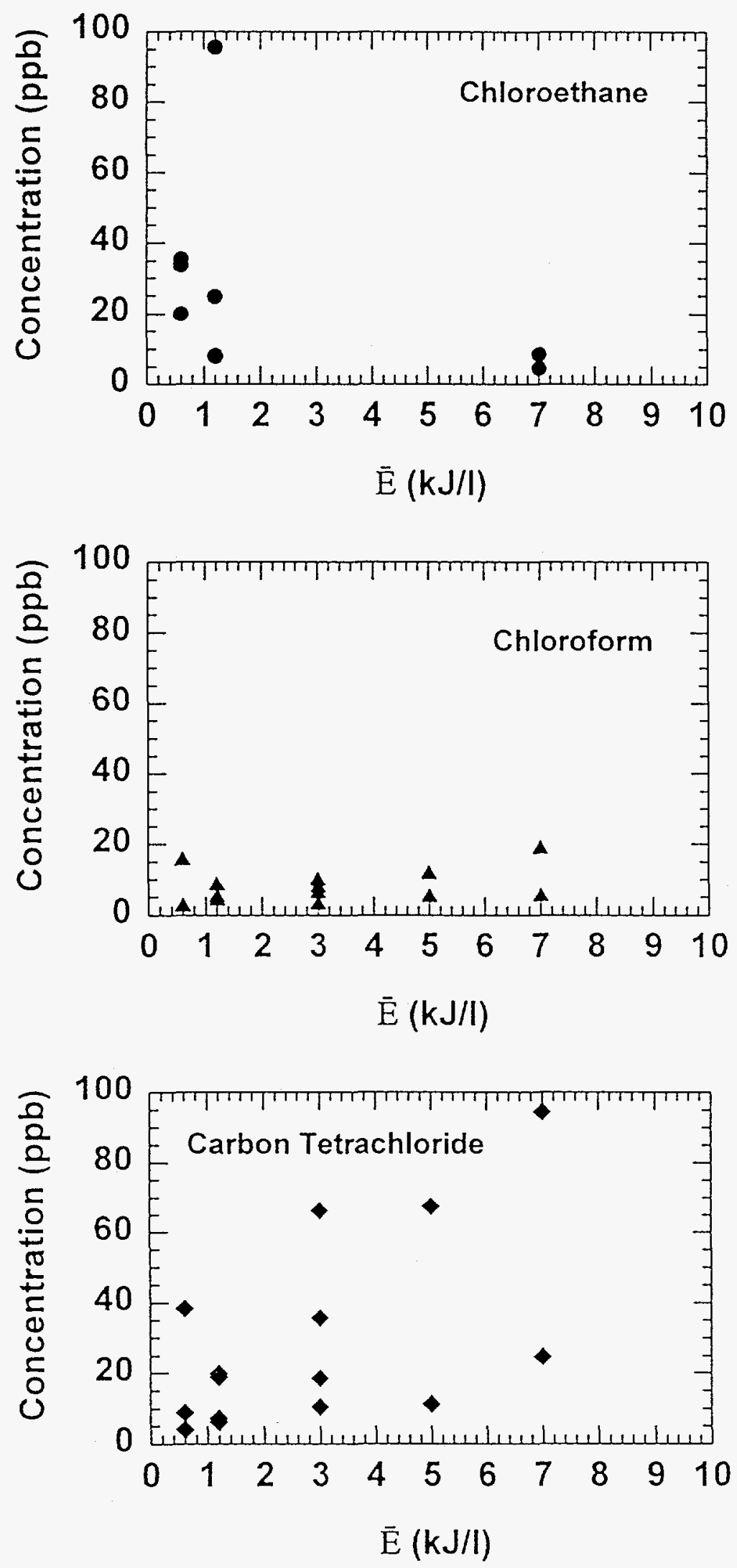

Figure 13 
Appendix A

Silent Discharge Plasma (SDP) Background

\section{SDP Technical Overview}

The SDP is a form of nonthermal plasma, which is easily created by a dielectric-ballasted electrical discharge. Nonthermal plasmas are characterized by conditions in which the various plasma species are not in thermal equilibrium - that is, electrons, ions, and neutral species have different temperatures, with the less massive electrons having the highest temperature (e.g., 1-10 eV). Gas-phase pollutants are decomposed by the free radicals or electrons generated by these plasmas. Nonthermal plasmas show promise for simultaneously treating different types of pollutants such as many VOCs, flue gases $\left(\mathrm{SO}_{x}\right.$ and $\mathrm{NO}_{\mathrm{x}}$ ), and other hazardous chemicals.

A dielectric-barrier electrical discharge is produced when one or both electrodes are covered with a dielectric. This arrangement provides a self-terminating discharge which is relatively independent of applied voltage waveshape. At gas pressures of order one atmosphere, gap spacings of order a few millimeters, and the application of alternating high voltage (e.g., $50 \mathrm{~Hz}$ to several $\mathrm{kHz}$ ), a large number of "microdischarges", statistically spread in space and time over the electrode area, are created in the gas. Most evidence suggests that barrier discharges are generally described by a Townsend avalanche followed by a discharge streamer. The microdischarge streamers (cylindrical current filaments with typical radius of order $100 \mu \mathrm{m}$ ) are transient discharges (e.g., lasting only a few nanoseconds for oxygen or air), fed by ionization and detachment and then arrested when charge build-up on the dielectric reduces the electric field in the streamer to the point where electron attachment becomes dominant.

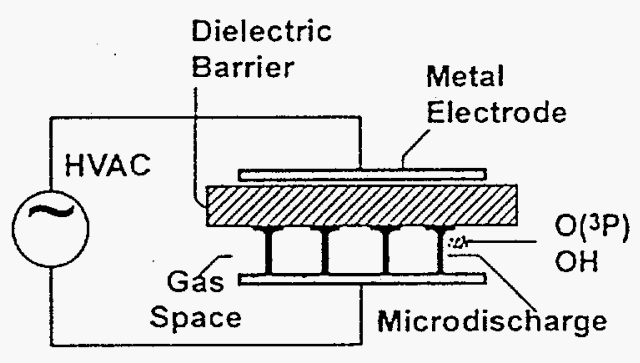

Fig. A-1: Diagram of a single-dielectricbarrier discharge plasma reactor.
The barrier discharge configuration was first reported in 1857 by von Siemens, was named the silent discharge by Warburg who investigated it around the turn of the century, and has been widely used for the generation of ozone. Figure A-1 shows a single-barrier reactor schematic diagram. Corona discharges produce plasmas similar to barrier discharges but take advantage of their natural electric-field inhomogeneity to terminate the discharge, rather than charge buildup on a dielectric barrier.

In nonthermal plasmas, electrical energy is used to create large quantities of highly reactive free radicals (especially atomic oxygen $\mathrm{O}\left({ }^{3} \mathrm{P}\right)$ and hydroxyls $\mathrm{OH}$ ) in a gaseous medium. For many compounds, the free radicals initiate the decomposition of the 
pollutants. At the relatively high plasma electron temperatures of an atmosphericpressure barrier discharge, $\mathrm{O}$-atoms and $\mathrm{OH}$ radicals are produced by reactions such as

$$
\begin{aligned}
& \mathrm{e}+\mathrm{O}_{2} \rightarrow \mathrm{O}\left({ }^{3} \mathrm{P}\right)+\mathrm{O}\left({ }^{\mathrm{l}} \mathrm{D}\right)+\mathrm{e} \\
& \mathrm{O}\left({ }^{1} \mathrm{D}\right)+\mathrm{H}_{2} \mathrm{O} \rightarrow 2 \mathrm{OH} .
\end{aligned}
$$

Complex molecules, like many VOCs, will often undergo a series of reactions before the final products result. At high plasma electron temperatures, the decomposition of a gasphase chlorocarbon like trichloroethylene (TCE) is dominated by free-radical reactions.

$$
\mathrm{O}\left({ }^{3} \mathrm{P}\right) \text { or } \mathrm{OH}+\mathrm{C}_{2} \mathrm{HCl}_{3} \rightarrow \mathrm{CO}_{2}+\mathrm{CO}+\mathrm{HCl}+\mathrm{Cl}_{2}+\mathrm{COCl}_{2}+\cdots \text {. }
$$

Strongly electron-attaching molecules, like $\mathrm{CCl}_{4}$, are preferentially decomposed by dissociative attachment at low plasma electron temperatures, but direct electron-induced dissociation and radical attack dominate at high electron energies. For $\mathrm{CCl}_{4}$, dissociative attachment is expected to be more advantageous than radical attack because $\mathrm{Cl}$ and $\mathrm{ClO}$ radicals resulting from $\mathrm{O}$ and $\mathrm{OH}$ reactions with $\mathrm{CCl}_{4}$ drive circular kinetics which can reform it.

Fortunately, some commonly-formed hazardous byproducts (like phosgene $\mathrm{COCl}_{2}$ ) are unstable and are quickly destroyed by reacting with liquid water or water vapor. In practice, a water-based scrubber can be easily employed to destroy phosgene and neutralize the acids which are an inevitable decomposition product of chlorinated hydrocarbons.

The key scaling parameter for decomposition is the plasma energy density, or the electrical energy per unit volume deposited in the treated gas. This can also be expressed as the electrical power $\mathrm{P}$ deposited in the gas divided by the gas flow rate $\mathrm{Q}$, or $\mathrm{P} / \mathrm{Q}$. We normally use units of $\mathrm{J} / 1$ iter or $\mathrm{J} / \mathrm{cm}^{3}$ for P/Q. In many cases, the removal of a pollutant approximately scales as an exponential function of $P / Q$, so the degree of removal of a given species is given by

$$
-\log \left([\mathrm{X}] /[\mathrm{X}]_{0}\right)=(\mathrm{P} / \mathrm{Q}) / \alpha,
$$

where $[\mathrm{X}]_{0}$ and $[\mathrm{X}]$ are the initial and post-treatment concentrations of species $\mathrm{X}$, respectively and $\alpha$ is the characteristic energy density for one decade removal. With this scaling, to maintain a fixed energy density (and a corresponding fixed degree of removal), the power must be increased in proportion to the gas flow rate.

\section{SDP Applications}

Application of SDP to the destruction of organic compounds, although explored for several years, has become fairly common only in the last few years. Initial work on the destruction of nerve gases and flue gas cleanup has expanded to many hydrocarbon and halocarbon compounds, generally with promising results. Near complete destruction of 
many hydrocarbons and chlorocarbons has been demonstrated. At Los Alamos, we have developed the silent discharge plasma process for treating hazardous organic wastes, particularly VOCs. Experiments at Los Alamos have been related to aliphatic hydrocarbons, chlorocarbons - e.g., TCE (trichloroethylene $\mathrm{C}_{2} \mathrm{HCl}_{3}$ ), TCA

(trichloroethane $\mathrm{C}_{2} \mathrm{H}_{3} \mathrm{Cl}_{3}$ ), $\mathrm{PCE}$ (tetrachloroethylene or perchloroethylene $\mathrm{C}_{2} \mathrm{Cl}_{4}$ ) and carbon tetrachloride $\left(\mathrm{CCl}_{4}\right.$ ), and $\mathrm{CFCs}$ (chloro-fluorocarbons) using silent discharges.

SDP chemical reactors can be used to treat industrial-process off-gas streams, stack-gases from primary treatment units (e.g., incinerators), or solvents/volatile chemicals in soil or groundwater. In treating chemicals in soil or groundwater, the chemicals must be transferred to the vapor phase, a step usually accomplished by a vacuum pump or a vacuum-sparger system. Heterogeneous wastes (e.g., solvent-contaminated solids) can also be treated by applying heat to volatilize the solvents and then flushing with an inert carrier gas (e.g., Ar or $\mathrm{N}_{2}$ ).

\section{Anticipated Advantages of SDP Processing}

SDP technology has shown strong potential for a high degree of hazardous compound cleanup and is expected to have these distinct advantages over conventional technologies:

- NTP treatment is not incineration;

- NTP operates at near-ambient pressures and temperatures;

- No fuel is added to the process, which minimizes secondary wastes;

- NTP can simultaneously remove hazardous organics and $\mathrm{SO}_{\mathrm{x}} / \mathrm{NO}_{\mathrm{x}}$ effluents;

- NTP processing can be easily implemented in a closed-loop mode;

- Feedback and automation potential are inherent features of the process;

- No precious, poisonous, or proprietary metal compounds (e.g., catalysts) are used. 


\section{Appendix B}

\section{Background on EPRI-LANL Collaboration}

As a representative of the major US electrical utilities, the Electric Power Research Institute (EPRI) has initiated programs that enable its utility members to assist their customers in producing less pollution and in meeting the recently-adopted Clean Air Act Amendments (CAAA 1990) standards. One area that looked promising for advanced air pollution control was nonthermal plasma (NTP) technology. In NTP, electrical energy is used to create active species (e.g., free radicals, electrons) that can degrade air toxins.

In 1990, the Los Alamos National Laboratory (LANL) started work on the particular NTP called silent discharge plasma (SDP) technology. This was being developed in collaboration with Auburn University and the University of Illinois for the treatment of VOC and $\mathrm{SO}_{x} \mathrm{NO}_{x}$ emissions within US Department of Energy (DOE) facilities. Motivated by the need to assist utility customers with air pollution problems and the increased emphasis on the transfer of government-developed technology to the private sector, EPRI and LANL negotiated a Collaborative Research and Development Agreement (CRADA) to develop SDP technology for the treatment of industrial air toxins in 1992. The CRADA was approved in 1993 and, under that partnership, a smallscale, mobile unit was designed and constructed for industrially-relevant field tests and technology demonstrations.

Figure B-1 shows a cross-section of the EPRI-LANL mobile unit. Two stacks of SDP cells, each with ten modular, parallel-flow, flat-plate cells, placed in a containment tank, comprise the plasma processor. Each set of twenty cells is driven by an $18-\mathrm{kW}$ rating sinusoidal-waveform power supply connected to a step-up transformer. Electrical power is measured by a combination of a voltage probe and a charge-measuring capacitor. Gas temperature, gas flow rate, and gas pressure are measured by thermocouples, flow meters, and pressure gauges. The electrical and gas-measuring instruments are interfaced to a computer-based data acquisition and analysis system. Gas sampling ports are located upstream of the plasma processor and downstream of the scrubber/neutralizer unit. A metal-bellows pump is placed in the inlet gas line to pump the gas stream through the plasma processor and scrubber/neutralizer. A back-up activated carbon filter is installed in the final exhaust output line to capture any pollutants (either unprocessed feed components or treatment byproducts) and to provide a safety feature in the event of an equipment processing failure. 


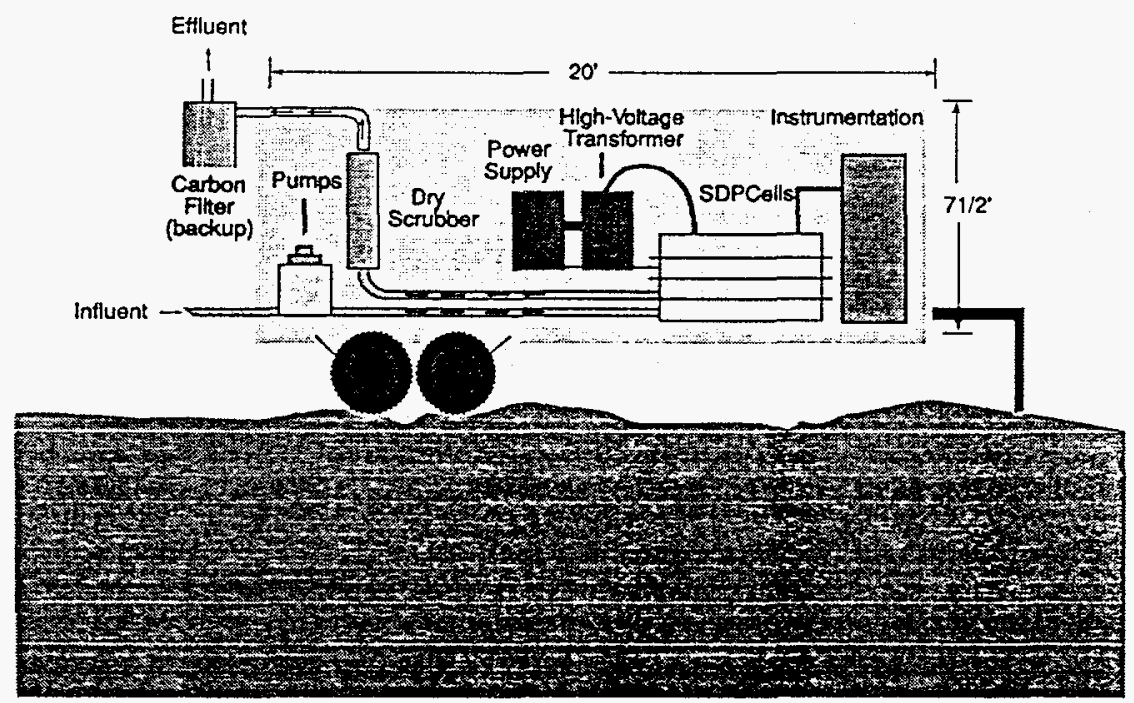

Fig.B-1: EPRI-LANL mobile silent discharge plasma processor. 